\title{
PENGARUH TASK TECHNOLOGY FIT, SYSTEM QUALITY DAN INFORMATION QUALITY TERHADAP USER PERFORMANCE: PERCEIVED USEFULNESS DAN PERCEIVED EASE OF USE SEBAGAI PEMEDIASI
}

\author{
Ida Bagus Gede Adi Permana \& Diki Putra Setianto
}

Universitas Airlangga

Email: Ibg.adipermana@feb.unair.ac.id

\begin{abstract}
Tujuan dilakukannya penelitian ini adalah untuk mengetahui pengaruh langsung atau tidak langsung system quality terhadap user performance karyawan FEB Universitas Airlangga sebagai pengguna sistem informasi cybercampus melalui kegunaan (perceived ease of use dan perceived usefulness). Penelitian ini menggunakan sampel yang berasal dari karyawan Fakultas Ekonomi Universitas Airlangga Surabaya. Pengambilan sampel untuk penelitian ini menggunakan purposive sampling yaitu teknik pengambilan sampel berdasarkan kriteria tertentu. berjumlah 58 responden. Hasil pengujian membuktikan bahwa system quality mempunyai pengaruh signifikan terhadap user performance karyawan FEB Universitas Airlangga. Perceived usefulness dan perceived ease of use belum mampu memediasi hubungan antara system quality terhadap user performance karyawan FEB Universitas Airlangga. Information quality mempunyai pengaruh signifikan terhadap user performance karyawan FEB Universitas Airlangga. Perceived usefulness dan perceived ease of use belum mampu memediasi hubungan antara information quality terhadap user performance karyawan FEB Universitas Airlangga. Task technology fit mempunyai pengaruh signifikan terhadap user performance karyawan FEB Universitas Airlangga. Perceived usefulness dan perceived ease of use belum mampu memediasi hubungan antara task technology fit terhadap user performance karyawan FEB Universitas Airlangga.
\end{abstract}

Kata kunci: system quality, information quality, task technology fit, perceived usefulness, perceived ease of use dan user performance 


\section{LATAR BELAKANG}

Banyaknya organisasi yang melakukan pembenahan di bidang teknologi informasi serta telekomunikasi maka diperlukan juga adanya upaya penyesuaian serta pembenahan sumber daya manusia (SDM). Pembenahan sumber daya manusia di setiap organisasi agar setiap SDM yang ada di organisasi tersebut dapat langsung siap dalam menerapkan serta menggunakan teknologi informasi yang akan dipakai oleh organisasi tersebut. Oleh karena itulah untuk mempermudah individu dalam memahami sistem informasi serta teknologi informasi yang ada di dalam organisasi mereka perlu ada sebuah model yang mempermudah individu dalam mempelajari serta menerima sistem informasi maka disitulah muncul TAM (Technology Acceptance Model) sebagai salah satu model yang dapat digunakan dalam membantu mengetahui seberapa besar individu dapat menerima teknologi serta sistem yang baru.

TAM sendiri menurut Davis (1989) adalah teori sistem informasi yang membuat model tentang bagaimana pengguna mau menerima dan menggunakan teknologi. Model ini mengusulkan bahwa ketika pengguna ditawarkan untuk menggunakan suatu sistem yang baru, sejumlah faktor mempengaruhi keputusan mereka tentang bagaimana dan kapan akan menggunakan sistem tersebut, khususnya dalam hal usefulness (pengguna yakin bahwa dengan menggunakan sistem ini akan meningkatkan kinerjanya), ease of use (di mana pengguna yakin bahwa menggunakan sistem ini akan membebaskannya dari kesulitan, dalam artian bahwa sistem ini mudah dalam penggunaannya).

Menurut Gomez (2000:142), ukuran performansi yang bersifat kuantitatif seperti satuan-satuan produksi dan volume penjualan menghasilkan pengukuran yang konsisten secara relatif. Kriteria-kriteria yang sifatnya subyektif, seperti sikap, kreativitas, dan kerjasama, menghasilkan pengukuran yang kurang konsisten, tergantung pada siapa yang mengevaluasi, dan bagaimana pengukuran itu dilakukan. Ali dan Boujelbene (2013) pengukuran user performance adalah memberikan dampak positif terhadap produktivitas karyawan, mengurangi waktu yang dibutuhkan untuk menyelesaikan tugas-tugas, menyelesaikan berbagai masalah sekaligus dalam pekerjaan, menyelesaikan tugas-tugas karyawan agar lebih cepat, memungkinkan karyawan untuk melakukan lebih banyak pekerjaan daripada sebelumnya, meningkatkan kualitas kinerja, membantu karyawan untuk memecahkan masalah ketenagakerjaan, mengurangi kesalahan karyawan yang berhubungan dengan kinerja, meningkatkan efisiensi dalam pekerjaan, meningkatkan kreativitas karyawan, membantu untuk membuat ide-ide baru dari diri karyawan dan mencapai tujuan pekerjaan.

Selain faktor pengukuran kinerja diatas ternyata ada faktor lain yang memberikan dampak terhadap sistem informasi dan kinerja individu, yaitu menurut Stone dkk (2006:465-482) dalam studinya mampu menyajikan suatu model teoritis yang menghubungkan kualitas informasi, kualitas sistem dan tugas-tugas yang dilakukan pada sebuah organisasi sehingga dapat ditemukan jika penggunaan sistem informasi akan memberikan dampak terhadap kinerja individu di sebuah organisasi, sehingga dari model awal TAM dapat diketahui jika TAM dapat mempengaruhi kinerja individu asalkan ada faktor-faktor lain yang dapat mendukung keberhasilan penerapan sistem informasi di sebuah organisasi dan faktor-faktor itu adalah System Quality (Kualitas Sistem), Information Quality (Kualitas Informasi), dan Task Technology Fit (Teknologi Tugas Fit).

Adanya cybercampus merupakan upaya Universitas Airlangga untuk menjadikan kampus tersebut berbasis teknologi informasi. Usaha tersebut diterapkan di semua lini. Mulai dari 
sistem pembelajaran, kurikulum, fasilitas, maupun sarana dan prasarana lainnya, semuanya dikembangkan dengan basis teknologi. Adanya perkembangan teknologi informasi yang menuntut untuk menyelesaikan proses pengolahan informasi secara cepat dan fleksibel, maka kebutuahan dari metode manual ke otomatis sudah menjadi keharusan untuk dipenuhi. Namun, bukan berarti meninggalkan seluruh proses manual dan memangkas tenaga kerja, sebab banyak aspek-aspek lain yang harus menjadi pertimbangan dalam melakukan otomatisasi dikantor. Keberhasilan suatu sistem informasi akan tergantung pada kemudahan dan pemanfaatan pemakai sistem terhadap teknologi yang ada dalam sistem karena teknologi akan membantu individu dalam menyelesaikan tugasnya (Goodhue, 1995). Satu hal penting yang harus diperhatikan oleh perusahaan atau pelaku bisnis yang menerapkan teknologi informasi adalah sejauh mana keberhasilan sistem tersebut membawa dampak positif dalam peningkatan kinerja baik individual maupun organisasi secara keseluruhan.

Sistem informasi Cybercampus Universitas Airlangga pada awalnya mulai dibuat sekitar tahun 2010. Cybercampus pada awalnya dibentuk sebagai sebuah sistem yang dapat menjadi penghubung antara berbagai urusan yang menyangkut semua kebutuhan serta urusan yang menyangkut proses perkuliahan pada semua mahasiswa yang ada di Universitas Airlangga. Saat ini Cybercampus digunakan untuk pengelolaan aktivitas akademik berupa KRS, KHS, input nilai sampai absensi perkulihan serta pengelolaan aktivitas keuangan. Hal ini bertujuan untuk memudahkan pengelolaan aktivitas akademik agar tidak terjadi antrian dari kalangan mahasiswa. Karyawan yang memanfaatkan adanya Cybercampus adalah bagian akademik, bagian keuangan, bagian kemahasiswaan, bagian perlengkapan, bagian sistem informasi dan bagian sumber daya manusia. Hal ini bertujuan untuk memudahkan pekerjaan dari masing-masing bagian dan dapat tersambung dengan masing-masing bagian.

Nampak bahwa penelitian tentang sebagai mana pentingnya keberadaan serta peran dari sistem informasi dalam mendukung kinerja SDM sangatlah besar sehingga dibutuhkan pembelajaran yang kontinu agar setiap SDM mampu memahami secara maksimal dari kegunaan dari sistem informasi yang ada di sebuah organisasi, seperti halnya Universitas Airlangga, agar dapat diketahui sejauh mana kesesuaian karakteristik tugas, kualitas informasi dan kualitas sistem mempengaruhi kinerja pengguna dari sistem informasi cybercampus yang ada di Universitas Airlangga.

\section{TINJAUAN LITERATUR}

Pada dasarnya sistem adalah suatu kerangka dari prosedur-prosedur yang saling berhubungan, yang disusun sesuai dengan skema yang menyeluruh untuk melaksanakan suatu kegiatan atau fungsi utama dari perusahaan yang dihasilkan oleh suatu proses tertentu yang bertujuan untuk menyediakan informasi untuk membantu mengambil keputusan manajemen operasi perusahaan dari hari ke hari serta menyediakan informasi yang layak untuk pihak di luar perusahaan. Pengertian Sistem yang dikemukakan oleh para ahli adalah sebagai berikut:

Menurut Ramachandra dan Srinivas (2012) sistem adalah suatu elemen yang saling terorganisir antara satu dengan lainnya yang dapat diatur serta bergabung bersama untuk mencapai suatu tujuan. Sistem juga sering memiliki beberapa tujuan. Sistem yang dimaksud menggunakan perangkat keras dan perangkat lunak yang ada di dalam komputer, 
prosedur manual, manajemen dan pengambilan model dan basis data. Sebuah sistem terdiri dari sub-sistem, yang dapat disusun menjadi sub-sistem lebih yang lanjut. Sub-sistem mengirim dan menerima data dari satu sama lain. Menurut O'Brien dan Marakas (2007) sistem adalah seperangkat komponen yang saling terkait, dengan batas yang jelas, bekerja sama untuk mencapai seperangkat tujuan dengan menerima input dan menghasilkan output dalam proses transformasi yang terorganisir. Banyak contoh dari sistem dapat ditemukan dalam ilmu fisika dan biologi, teknologi modern, dan dalam masyarakat manusia.

Sistem dapat memberikan informasi bagi penggunanya, sistem yang berkualitas dapat memberikan informasi yang tepat bagi penggunanya. Menurut DeLone dan McLean (2003) kualitas sistem dapat diukur serta dapat dirasakan dari kemudahan penggunaan, kehandalan, fungsionalitas, fleksibilitas, kualitas data, integrasi dan portabilitas, yang mencerminkan kebutuhan pengguna ketergantungan pada kualitas sistem. Namun, dari sudut pandang praktis, tingkat kualitas yang tinggi dari sebuah sistem dapat memberikan kenyamanan bagi pengguna serta privasi lebih dan respon yang lebih cepat. Misalnya, menurut Lederer et al (2006) telah menunjukkan bahwa kapasitas sistem telah memiliki dampak positif yang dirasakan kemudahan penggunaan dan kegunaan dirasakan dari sistem.

Kualitas suatu sistem informasi digunakan untuk mengukur kesuksesan secara teknik. Tingkatan teknikal komunikasi diartikan sebagai keakuratan dan keefisienan sistem komunikasi yang menghasilkan informasi (Shannon dan Weaver, 2003). Menurut Livari (2005) kualitas sistem informasi merupakan sistem yang memiliki ciri karakteristik kualitas yang diinginkan dari sistem informasi itu sendiri dan kualitas informasi dari produk. Menurut Jogiyanto, (2005:10) kualitas informasi harus terdiri dari:

1. Akurat, berarti informasi harus bebas dari kesalahan-kesalahan dan tidak bias atau menyesatkan. Akurat mencerminkan maksud dari informasi tersebut. Informasi harus akurat karena dari sumber informasi sampai kepenerima informasi kemungkinan banyak terjadi gangguan (noise) yang dapat merubah atau merusak informasi tersebut.

2. Tepat pada waktunya, informasi yang datang pada penerima tidak boleh terlambat. Informasi yang sudah usang tidak akan mempunyai nilai lagi karena informasi merupakan landasan dalam proses pengambilan keputusan. Bila pengambilan keputusan terlambat, maka dapat berakibat fatal untuk organisasi. Untuk itu kecepatan informasi saat ini sangat diperlukan. Dalam memberikan informasi dengan cepat maka diperlukan teknologi-teknolog mutakhir dalam mengolah ataupun proses pengiriman informasi.

3. Relevan, informasi tersebut mempunyai manfaat untuk pemakainya. Karena relevansi informasi untuk setiap orang itu berbeda-beda

Berdasarkan pengertian di atas bahwa kualitas informasi di ukur dari, akurat, tepat pada waktunya dan relevan. Kualitas informasi di ukur dari ke akuratan yang berarti informasi harus bebas dari kesalahan yang di informasikan. Informasi yang tidak akurat maka akan menghasilkan kualitas informasi yang salah kepada orang yang akan di informasikan. 
Kualitas informasi menurut beberapa ahli diatas diukur berdasarkan sembilan karakteristik yaitu akurasi, hubungan, kelengkapan, kelengkapan waktu, keringkasan, jumlah yang tepat dari informasi, konsistensi, mudah dimengerti, dan aksesbilitas yang diartikan tersendiri, tetapi pada penelitian Ali dan Boujelbene (2013) sembilan karakteristik tersebut dijabarkan menjadi sepuluh pengukuran. Pada penelitian ini pengukuran kualitas informasi didasarkan pada penelitian Ali dan Boujelbene (2013) adalah:

1. Membantu mendapatkan informasi yang akurat

2. Memberikan informasi yang relevan

3. Membantu memberikan informasi yang tepat dengan waktu yang singkat

4. Informasi yang terkandung dalam komputer diperbarui secara teratur dan tepat waktu

5. Dapat meningkatkan kualitas pekerjaan

6. Dapat menemukan informasi yang lengkap jika diperlukan

7. Cukup untuk menyelesaikan pekerjaan

8. Dapat di akses dengan mudah

9. Mudah saudara dapatkan

10. Menghemat waktu dalam menyelesaikan pekerjaan

Task Technology Fit (TTF) merupakan kesesuaian dari kapabilitas teknologi untuk kebutuhan tugas dalam pekerjaan yaitu kemampuan teknologi informasi untuk memberikan dukungan terhadap pekerjaan (Goodhue dan Thompson, 1995 dalam Dishaw et al, 2002). Model TTF memiliki empat konstruk kunci yaitu task characteristics, technology characteristics yang bersama-sama mempengaruhi konstruk tiga TTF yang balik mempengaruhi variabel outcome yaitu performance atau utilization. Model TTF menempatkan bahwa teknologi informasi hanya akan digunakan jika fungsi dan manfaatnya tersedia untuk mendukung aktivitas pengguna.

Task Technology Fit (TTF) merupakan korespondensi antara tugas, kemampuan individu, dan fungsi teknologi. Artinya kemampuan individu dalam menyelesaikan tugas tersebut didukung adanya fungsi dari teknologi. Menurut Goodhue dan Thomson (1995) keberhasilan sistem informasi suatu perusahaan bergantung pada pelaksanaan sistem tersebut, kemudahan bagi pemakai, dan pemanfaatan teknologi yang digunakan. Goodhue dan Thomson (1995) menyatakan bahwa pemakai akan memberikan nilai evaluasi yang positif tidak hanya karena karakteristik sistem yang melekat, tetapi lebih pada sejauh mana sistem dapat memenuhi kebutuhan tugas pemakai. Model evaluasi ini pertama kali dikembangkan oleh Goodhue dan Thompson (1995). Teoti TTF berpegang bahwa teknologi informasi memiliki dampak positif terhadap kinerja individu dan dapat digunakan jika kemampuan teknologi informasi cocok dengan tugas-tugas yang harus dihasilkan oleh karyawan (Furneaux, 2006)

Task Technology Fit (TTF) adalah kerangka teoritis didirikan dalam penelitian sistem informasi yang memungkinkan penyelidikan isu fit dari teknologi untuk tugas serta kinerja. Salah satu fokus yang signifikan dari TTF telah di individu untuk menilai dan menjelaskan keberhasilan sistem informasi dan dampak pada kinerja individu (Goodhue \& Thompson, 1995). Goodhue dan Thompson mengusulkan rantai teknologi ke kinerja yang di mana terdapat karakteristik IT, tugas, dan pengguna individu menjelaskan penggunaan sistem informasi dan kinerja individu. Hasil empiris menunjukkan bahwa TTF dan penggunaan bersama-sama lebih menjelaskan dampak TI terhadap kinerja serta tugas individu pengguna Teknologi Informasi. Penelitian lebih lanjut telah menunjukkan fungsi serta konstruk dari TTF adalah untuk mengukur nilai dari suatu teknologi informasi (Goodhue \& Thompson, 1995) serta untuk memprediksi kinerja (Goodhue, Klein, \& Maret, 2000). Hubungan TTF dapat menginformasikan 


\section{Ida Bagus Gede Adi Permana Diki Putra Setianto}

hubungan antara tugas dan penggunaan teknologi dari sejumlah perspektif: peningkatan kinerja (Carswell, Thomas, Petre, Price, \& Richards, 2000); perubahan persepsi pengguna (Wenger \& Carlson, 1995) atau peningkatan utilisasi pengguna (Kim \& Malhotra, 2005; Ngai, Poon, \& Chan, 2007; Venkatesh, Morris, Davis, \& Davis, 2003).

TTF berkaitan dengan sejauh mana teknologi memenuhi persyaratan terkait tugas-tugas sebuah konstruksi yang konseptual berkaitan dengan TAM (model penerimaan teknologi) membangun dari yang dirasakan pengguna. TTF dapat memberikan panduan untuk desain teknologi atau tugas. TTF mengeksplorasi hubungan antara tugas individu dan teknologi profil fit dengan mengukur kinerja pengguna dan pemanfaatan teknologi.

Perceived usefulness didefinisikan sebagai "sejauh mana seseorang percaya bahwa dengan menggunakan sistem tertentu dapat meningkatkan kinerja para penggunanya, hal ini mengikuti dari definisi dari kata "Usefull (berguna)" di definisikan sebagai mampu, digunakan serta menguntungkan. Akan tetapi disesuaikan dengan konteks organisasi, sehingga mampu menghasilkan SDM yang baik serta mempunyai dampak yang baik dalam memperbaiki kinerja dengan kenaikan gaji, promosi, bonus, dan penghargaan lainnya bagi karyawan (Pfeffer, 1982; Schein, 1980; Vroom, 1964).

Perceived Usefulness mengacu pada apakah sistem menyediakan informasi yang akurat, tepat waktu, relevan, dapat diandalkan dan valid untuk pengguna atau tidak (Miller, 2007). Oleh karena itu, menggunakan sistem akan meningkatkan prestasi kerja, produktivitas, efisiensi dan kualitas kerja. Menurut Bhattacherjee (2002), kesediaan seseorang untuk berinteraksi dengan sistem tertentu sudah dianggap berguna. Dengan demikian, diharapkan pengguna akan mengadopsi sistem jika mereka percaya bahwa itu akan membantu mereka untuk mencapai hasil yang diinginkan dari kinerja (Amoako-Gyampah and Salam, 2004:731 - 745).

Perceived Usefulness dianggap sebagai istilah untuk keinginan individu agar dapat meningkatkan produktivitas dan kinerja pengguna/ individu (Rajiv, Anand dan Charles, 2006:1849-1864). Selain itu, menurut Wixom dan Watson (2001) menemukan bahwa Information quality (kualitas informasi), system quality (kualitas sistem) dan Perceived usefulness (kegunaan dirasakan) terkait satu sama lain, yang menyatakan bahwa semakin tinggi tingkat kualitas informasi dan kualitas sistem, semakin tinggi sistem berguna.

Kemudahan penggunaan merupakan tingkatan dimana seseorang percaya bahwa teknologi informasi mudah untuk dipahami (Davis, 1989). Intensitas penggunaan dan interaksi antara pengguna (user) dengan sistem juga dapat menunjukkan kemudahan penggunaan. Sistem yang sering digunakan menunjukkan bahwa sistem tersebut lebih dikenal lebih mudah dioperasikan dan lebih mudah digunakan oleh penggunanya (Goodwin dan Silver dalam Adam et al., 1992:229).

Menurut Senn (2008:16) "user or end-user is people who use information technology in their jobs or personal lives". Artinya user atau pengguna akhir adalah orang yang menggunakan teknologi di dalam pekerjaan mereka atau kehidupan pribadi. "Users in a computing context refers to one who uses a computer system. Users may need to identify themselves for the purposes of accounting, security, logging and resource management. In order to identify oneself, a user has an account (a user account) and a username, and in most cases also a password. Users employ the user interface to system" (Senn, 2008:17). Artinya, user dalam konteks komputerisasi adalah orang yang menggunakan sebuah sistem komputer. User mungkin butuh melakukan indentifikasi untuk tujuan akuntansi, keamanan, logging dan 
manajemen sumber daya. Dalam upaya mengidentifikasi dirinya, seorang user memiliki sebuah account (sebuah account pengguna) dan sebuah username, dan kebanyakan juga memiliki sebuah password. User menggunakan user interface untuk masuk ke dalam sistem.

\section{METODOLOGI}

Populasi pada penelitian ini adalah seluruh karyawan Fakultas Ekonomi Universitas Airlangga Surabaya. Pengambilan sampel untuk penelitian ini menggunakan purposive sampling yaitu teknik pengambilan sampel berdasarkan kriteria tertentu. Adapun kriteria yang telah ditentukan adalah:

1. Karyawan menggunakan sistem Cybercampus Universitas Airlangga secara berkala.

2. Karyawan memiliki akun atau akses langsung ke sistem Cybercampus Universitas Airlangga

Berdasarkan kriteria tersebut maka jumlah sampel pada penelitian ini sebesar 58 responden yang terdiri dari 6 bagian yaitu Staf Bagian Akademik, Staf Bagian Keuangan, Staf Bagian Kemahasiswaan, Staf Bagian Perlengkapan, Staf Bagian Sistem Informasi dan Staf Bagian SDM.

\section{HASIL}

Hipotesis pertama menyatakan bahwa terdapat pengaruh system quality terhadap user performance karyawan FEB Universitas Airlangga. Setelah dilakukan pengujian system quality terbukti memiliki pengaruh terhadap user performance karyawan FEB Universitas Airlangga. Hasil tabulasi data menunjukkan "kualitas sistem yang dapat dipercaya" memiliki nilai tertinggi di bandingkan dengan indikator lainnya. Hal ini dapat dikatakan bahwa kualitas sistem yang dipakai oleh FEB Universitas Airlangga dapat dipercaya, hal ini ditunjukkan dengan data-data yang dibutuhkan oleh mahasiswa selalu diperbaharui oleh karyawan FEB Universitas Airlangga. Adanya kualitas sistem yang dapat dipercaya membuat FEB Universitas Airlangga sebagai Universitas yang menerapkan cybercampus untuk memudahkan terhubungnya antara mahasiswa dan pihak kampus. Pembaharuan data dari masingmasing mahasiswa menunjukkan tingginya user performance karyawan FEB Universitas Airlangga.

Terdapat pengaruh system quality terhadap user performance karyawan FEB Universitas Airlangga melalui perceived usefulness. Setelah dilakukan pengujian pengaruh system quality terhadap melalui perceived usefulness memiliki nilai lebih kecil bila dibandingkan dengan pengaruh langsung system quality terhadap user performance karyawan FEB Universitas Airlangga. Perceived usefulness belum mampu memediasi hubungan antara system quality terhadap user performance karyawan FEB Universitas Airlangga. Dapat diartikan bahwa hubungan system quality terhadap user performance melalui perceived usefulness merupakan pengaruh secara partially mediated. Rendahnya perceived usefulness disebabkan, FEB Universitas Airlangga pada dasarnya sudah memiliki sistem yang komputerais tetapi belum terhubungan antar bagian. Adanya sistem cybercampus memudahkan terhubungannya antar bagian di FEB Universitas Airlangga.

Pengukuran kualitas sistem informasi adalah suatu proses multidimensional yang berfokus pada aspek yang berbeda, karena sistem memiliki banyak aspek seperti aspek sistem, aspek kualitas dan aspek lain yang berkaitan dengan masalah teknis. Secara umum, ukuran kualitas sistem berkonsentrasi pada spesifikasi dari sistem target. Namun, beberapa studi 


\section{Ida Bagus Gede Adi Permana Diki Putra Setianto}

telah meneliti manfaat dan penggunaan sistem dan efisiensi. Beberapa studi telah menggunakan kehandalan, waktu respon dan kemudahan penggunaan seperti yang disebutkan dalam berbagai penelitian untuk mendukung peningkatan kinerja dari pengguna sistem informasi agar dapat bekerja dengan lebih baik lagi sehingga meningkatakan keefektivitasan mereka dalam mengakses informasi yang ada di dalam organisasi tersebut (Alloway, R, 2007).

\section{KEPUTUSAN}

Terdapat pengaruh system quality terhadap user performance karyawan FEB Universitas Airlangga melalui perceived ease of use. Setelah dilakukan pengujian pengaruh system quality terhadap melalui perceived ease of use memiliki nilai lebih kecil bila dibandingkan dengan pengaruh langsung system quality terhadap user performance karyawan FEB Universitas Airlangga. Perceived ease of use belum mampu memediasi hubungan antara system quality terhadap user performance karyawan FEB Universitas Airlangga. Dapat diartikan bahwa hubungan system quality terhadap user performance melalui perceived ease of use merupakan pengaruh secara partially mediated.

Rendahnya perceived ease of use dalam menghubungkan system quality terhadap user performance, disebabkan oleh sebagian besar karyawan FEB Universitas Airlangga memiliki pendidikan minimal S1, dimana karyawan yang memiliki pendidikan sarjana sudah memiliki keterampilan dibidang komputer. Disamping itu, pekerjaan di FEB Universitas Airlangga tidak memerlukan keahlian yang khusus, hanya memerlukan ketelitian dari karyawan karena pekerjaan di FEB Universitas Airlangga hannya berhubungan dengan administrasi.

Hipotesis kedua menyatakan bahwa terdapat pengaruh information quality terhadap user performance karyawan FEB Universitas Airlangga. Setelah dilakukan pengujian information quality yang ada di FEB Universitas Airlangga terbukti memiliki pengaruh terhadap user performance. Hal ini dibuktikan dengan hasil tabulasi data yang menunjukkan "kualitas informasi yang mudah di dapatkan oleh karyawan" memiliki rata-rata tertinggi jika dibandingkan dengan indikator lainnya. Kemudahan mendapatkan informasi sangat penting bagi karyawan FEB Universitas Airlangga karena informasi yang benar-benar berkualitas sangat dibutuhkan oleh mahasiswa. Informasi yang ada di FEB Universitas Airlangga tidak hanya dibutuhkan oleh karyawan saja tetapi juga dibutuhkan oleh mahasiswa. Bagi karyawan dan mahasiswa FEB Universitas Airlangga, informasi menjadi sangat penting dan berharga bila hanya diketahui oleh pihak tertentu saja, sehingga muncullah usaha-usaha pembatasan akses atas suatu informasi melalui berbagai metode pengamanan terhadap pihak yang tidak berkepentingan. Pemberian pembatasan akses informasi membuat kualitas informasi dapat dipercaya dan terjamin keakuratannya.

Terdapat pengaruh information quality terhadap user performance karyawan FEB Universitas Airlangga melalui perceived usefulness. Setelah dilakukan pengujian pengaruh information quality terhadap user performance karyawan FEB Universitas Airlangga melalui perceived usefulness memiliki nilai lebih kecil bila dibandingkan dengan pengaruh langsung information quality terhadap user performance. Perceived usefulness belum dapat memediasi hubungan antara information quality terhadap user performance. Dapat diartikan bahwa hubungan information quality terhadap user performance melalui perceived usefulness merupakan pengaruh secara partially mediated.

Rendahnya perceived usefulness dalam menghubungkan information quality terhadap user performance, disebabkan oleh kualitas informasi yang dibutuhkan oleh pengguna khususnya 


\section{Jurnal Manajemen Teori dan Terapan Tahun 10. No. 3, Desember 2017}

mahasiswa dan dosen sangat terlambat diketahui oleh mahasiswa. Ada beberapa informasi yang dibutuhkan oleh mahasiswa Fakultas Ekonomi dan Bisnis tidak bisa diakses di cybercampus, mahasiswa harus datang langsung ke bagian departemen maupun bagian akademi. Hal ini yang membuat rendahnya kualitas informasi yang dibutuhkan oleh penggunanya.

Terdapat pengaruh information quality terhadap user performance karyawan FEB Universitas Airlangga melalui perceived ease of use. Setelah dilakukan pengujian pengaruh information quality terhadap user performance karyawan FEB Universitas Airlangga melalui perceived ease of use memiliki nilai lebih kecil bila dibandingkan dengan pengaruh langsung information quality terhadap user performance. Perceived ease of use belum dapat memediasi hubungan antara information quality terhadap user performance. Dapat diartikan bahwa hubungan information quality terhadap user performance melalui perceived ease of use merupakan pengaruh secara partially mediated.

Terdapat beberapa pengaruh antara kualitas sistem informasi pada kinerja pengguna dan terdapat juga hubungan antara kualitas sistem informasi, terhadap kinerja dan produktivitas individu sehingga terdapat banyak penelitian yang meneliti hal tersebut (C. Yoon, dan T. Guimaraes, 1995), sehingga terdapat beberapa penelitian nyata yang dikaitkan dengan kinerja pengguna, dimulai dengan Davis (1989) dalam model penerimaan teknologi. Menurut V.Venkatesh, akk (2003) mengidentifikasi enam kategori utama keberhasilan sistem informasi: kualitas sistem, kualitas informasi, penggunaan, kepuasan pengguna, dampak individual, dan dampak organisasi (Todd, Adams \& Nelson, 1992) dalam ekstensi nya dari DeLone dan kerja McLean didefinisikan lebih lanjut kategori dan menambahkan beberapa variabel lagi.

Hipotesis ketiga menyatakan bahwa terdapat pengaruh task technology fit terhadap user performance karyawan FEB Universitas Airlangga. Setelah dilakukan pengujian task technology fit yang ada di FEB Universitas Airlangga terbukti memiliki pengaruh terhadap user performance. Hal ini dibuktikan dengan hasil tabulasi data yang menunjukkan "teknologi yang digunakan dapat menyelesaikan pekerjaan karyawan" memiliki rata-rata tertinggi jika dibandingkan dengan indikator lainnya. Berkembangnya teknologi yang ada saat ini dapat memudahkan karyawan dalam menyelesaikan pekerjaannya. Kecanggihan teknologi yang dimiliki oleh FEB Universitas Airlangga membuat karyawan merasa terbantukan dan dapat menyelesaikan pekerjaan secara tepat waktu, hal ini yang membuat kinerja pemakai terus mengalami peningkatan.

Sistem informasi diperkirakan memiliki dampak signifikan pada pekerjaan pengguna. Para peneliti telah mempelajari dampak dari sistem informasi terhadap pekerjaan pengguna dari perspektif yang berbeda dengan menggunakan pendekatan yang berbeda (J.Sviokla, 1990), (T. Saarinen, 1996) dan dengan mengukur beberapa faktor, yang meliputi perubahan kepentingan dari pekerjaan pengguna, jumlah pekerjaan yang dapat diselesaikan dan akurasi pekerjaan. Beberapa penelitian menegaskan bahwa sistem informasi meningkatkan produktivitas dan meningkatkan kinerja serta hasil (Y. Chav, 1996).

Menurut penelitan dari Goodhue, dan Thompson, (1995) memberikan arah baru bagi praktisi dan peneliti dengan meneliti kesesuaian antara sistem informasi, serta kebutuhan pengguna dan persyaratan tugas, yang pada gilirannya mempengaruhi kinerja pengguna. Meskipun mereka memberikan wawasan yang signifikan tentang sistem informasi serta dampaknya pada kinerja pengguna dan menjelaskan bagaimana sistem informasi menambah nilai kinerja individu. Banyak masalah yang harus diperhitungkan ketika menyelidiki sistem 


\section{Ida Bagus Gede Adi Permana Diki Putra Setianto}

informasi dan kinerja pengguna sebagai dibahas kemudian. Akhirnya, perlu menyebutkan bahwa tingkat hubungan antara semua faktor tersebut di atas berbeda dari lingkungan sistem informasi yang lain, tergantung pada karakteristik dari sistem dan pengguna. Namun, dalam mengembangkan desain penelitian, faktor-faktor yang di

Menurut penelitan dari Goodhue, dan Thompson, (1995) memberikan arah baru bagi praktisi dan peneliti dengan meneliti kesesuaian antara sistem informasi, serta kebutuhan pengguna dan persyaratan tugas, yang pada gilirannya mempengaruhi kinerja pengguna. Meskipun mereka memberikan wawasan yang signifikan tentang sistem informasi serta dampaknya pada kinerja pengguna dan menjelaskan bagaimana sistem informasi menambah nilai kinerja individu. Banyak masalah yang harus diperhitungkan ketika menyelidiki sistem informasi dan kinerja pengguna sebagai dibahas kemudian. Akhirnya, perlu menyebutkan bahwa tingkat hubungan antara semua faktor tersebut di atas berbeda dari lingkungan sistem informasi yang lain, tergantung pada karakteristik dari sistem dan pengguna. Namun, dalam mengembangkan desain penelitian, faktor-faktor yang dipilih.

\section{KESIMPULAN}

Berdasarkan hasil dan pembahasan yang telah dilakukan, maka simpulan yang dapat diambil adalah:

1. Hipotesis pertama menyatakan system quality memiliki pengaruh terhadap user performance karyawan FEB Universitas Airlangga. Hasil pengujian membuktikan, system quality mempunyai pengaruh terhadap user performance karyawan FEB Universitas Airlangga, dapat diartikan bahwa meningkatnya system quality akan diikuti oleh naiknya user performance karyawan FEB Universitas Airlangga. Apabila kualitas sistem yang dimiliki oleh FEB Universitas Airlangga berkualitas maka secara langsung akan meningkatkan user performance karyawan FEB Universitas Airlangga.

2. System quality memiliki pengaruh terhadap user performance karyawan FEB Universitas Airlangga melalui perceived usefulness. Hasil pengujian membuktikan, perceived usefulness tidak dapat memediasi hubungan antara system quality terhadap user performance karyawan FEB Universitas Airlangga. Hubungan system quality terhadap user performance karyawan FEB Universitas Airlangga melalui perceived usefulness merupakan hubungan secara partially mediated.

3. System quality memiliki pengaruh terhadap user performance karyawan FEB Universitas Airlangga melalui perceived ease of use. Hasil pengujian membuktikan, perceived ease of use tidak dapat memediasi hubungan antara system quality terhadap user performance karyawan FEB Universitas Airlangga. Hubungan system quality terhadap user performance karyawan FEB Universitas Airlangga melalui perceived ease of use merupakan hubungan secara partially mediated.

4. Hipotesis kedua menyatakan information quality memiliki pengaruh terhadap user performance karyawan FEB Universitas Airlangga. Hasil pengujian membuktikan, information quality mempunyai pengaruh terhadap user performance karyawan FEB Universitas Airlangga, dapat diartikan bahwa meningkatnya information quality akan diikuti oleh naiknya user performance karyawan FEB Universitas Airlangga. Apabila kualitas informasi yang dimiliki oleh FEB Universitas Airlangga berkualitas maka secara langsung akan meningkatkan user performance karyawan FEB Universitas Airlangga. 
5. Information quality memiliki pengaruh terhadap user performance karyawan FEB Universitas Airlangga melalui perceived usefulness. Hasil pengujian membuktikan, perceived usefulness tidak dapat memediasi hubungan antara information quality terhadap user performance karyawan FEB Universitas Airlangga. Hubungan information quality terhadap user performance karyawan FEB Universitas Airlangga melalui perceived usefulness merupakan hubungan secara partially mediated.

\section{DAFTAR PUSTAKA}

Adams, D.A., R.R. Nelson, P. A. Todd. 1992. Perceived Usefulness, Ease of Use and Usage of Information Technology: A Replication", MIS Quarterly, 16 (2), pp. 227-247.

Alloway, R. 2007. Defining Success for Data Processing: A Practical Approach to Stratégie Planning for the DP Department, Retrieved from http// business.clemson.edu

Al-Mamary ,Y.H. , \& Shamsuddin,A., dan Aziati ,N. 2014. The Role of Different Types of Information Systems in Business Organizations: A Review, International Journal of Research ,Vol.1, Issue.7,pp.333-339.

Amoako-Gyampah, K., and Salam, A. 2004. An Extension Of The Technology Acceptance Model In An ERP Implementation Environment. Information and Management 41(6), pp. $731-745$.

Bailey, J.E. and S.W Pearson.1983. Development of a Tool for Measuring and Analysing Computer Satisfaction, Management Science 29 May

Bhattacherjee, A. 2002. Individual Trust In Online Firms: Scale Development And Initial Test, Journal of Management and Information Systems, 9 (1), pp. 211-241.

Bovee, M. 2004. Information Quality: A Conceptual framework and Empirical Validation, Unpublished PhD Dissertation, University of Kansas, Kansas

C. Yoon, and T. Guimaraes. 1995. Assessing Expert Systems Impact On Users' Jobs. Journal of Management Information Systems, 12 (1), pp.225- 249.

Carswell, L., Thomas, P., Petre, M., Price, B., dan Richards, M. 2000. Distance Education Via The Internet: The student experience. British Journal of Educational Technology, 31 (1), 2946.

Chatzoglou, P.D., Vraimaki, E., Diamantidis, A. dan Sarigiannidis, L. 2010. Computer acceptance in Greek SMEs. Journal of Small Business and Enterprise Development, Vol. 17 No. 1, pp. 78 - 101.

Chin W Wynne, dan Todd Peter. 1995. On The use Usefullness, Ease of Use of Structural Equation Modeling in MIS Research: A Note of Caution. Management Information System Quarterly, 21 (3)

Davis, F. D. 1989. Perceived Usefulness, Perceived Ease Of Use, And User Acceptance of Information Technology. MIS Quarterly, 13(3), 319-339.

De Lone, W., and McLean, E. 1992. Information Systems Success: The Quest For The Dépendent Variable, Information Systems research 3(1), pp. 60-95.

. 2003. The DeLone McLean model of Information System Success: A Ten-Year Update, Journal of Management Information Systems, 19(4), pp. 3-9.

Dishaw, M. T., Strong D. M. and Bandy, D. B. 2002. Extending The TaskTechnology Fit Model With Self_Efficacy. Constructs Eighth Americas Conferences on Information System.

E.M. Moreau. 2006. The Impact of Intelligent Decision Support Systems On Intellectual Task Success: An empirical investigation. Decision Support Systems, (42) pp.593- 607.

Furneaux, B. 2006. Theories Used In IS Research: Technology Acceptance Model. Available from: www.istheory.yorku.ea 
Gomez, Faustino Cardoso. 2000. Manajemen Sumber Daya Manusia. Jakarta: Bumi Aksara.

Goodhue, D. L. and Thompson, R.L. 1995. Task-Technology Fit and Individual Performance. MIS Quarterly. 19(2): 213-236.

. 1998. Developmentien and Measurement Validity of A Task Technologi Fit Instrumen For User Evaluations of Information Sytem. Decision Sciences, Winter. 29(1): 105-138.

Goodhue, D., Klein, B, and March, S. 2000. User évaluations of IS As Surrogates For Objective Performance, Information \& Management, 38, pp. 87-101

Gorla, N., Somers, T.M., dan Wong, B. 2010 Organizational Impact Of System Quality, Information Quality, And Service Quality, Journal of Strategic Information Systems, Vol.19, pp.207-228.

Hair, Jr., dan Joseph F. 2008. Multivariate Data Analysis. New Jersey: Prentice Hall International.

Hasan, Y., Shamsuddin, A., dan Aziati, N. 2013. The Impact of Management Information Systems adoption in Managerial Decision Making: A Review, The International Scientific Journal of Management Information Systems, Vol.8, No.4,pp.010-017.

Huang, K., Lee, Y., and Wang, R. 1999. Quality Information and Knowledge, Upper Saddle River NJ: Prentice Hall

Igbaria, M., and Tan, M. 1997. The Conséquences of Information Technology Acceptance On Subséquent Individual Performance, Information \& Management, 32, pp. 113-121.

J.Sviokla. 1990.The Examination of The Impact of Expert Systems On The Firm: The Case of XCO. MIS Quarterly, 1 (June),pp.126-140.

Kahn, B. K., Strong, D. M., dan Wang, R. Y. 2002. Information quality benchmarks: product and service performance. Communications

Malhotra, Naresh K., Kim, Sung S., Agarwal, J. 2005. Internet Users' Information Privacy Concerns (IUIPC): The Construct, The Scale, and A Causal Model, Vol.15, No.4, pp.336355.

Lederer, L., Maupin, D., Sena, M., and Zhuang, Y. 2006. The Technology Acceptance Model and The World Wide Web, Décision Support Systems, 29, pp. 269-282.

Livari, J. 2005. An Empirical Test of The De Lone-Mc Lean Model of Information System Success, Database for Advances in Information Systems, 36(2), 2005, pp. 8-27.

Miller, H. 2007. The Multiple Dimensions of Information Quality, Article Retrieved from : http://www.muhlenberg.edu.

Mohamed Ali, Bejjar dan Boujelbene Younes. 2013. The Impact of Information Systems on user Performance: An Exploratory Study. Journal of Knowledge Management, Economics and Information Technology Issue 2, April.

Raymond, Lovis., Anne-Marie Croteau, dan Francis Bergeron. 2008. The Strategic Role of IT AS An Antecedent To The IT Sophistication And IT Performance of Manufacturing SMEs, Volume 4, No.3 \& 4

Seddon, P. A. 1997. Respecification And Extension of The DeLone and McLean Model of IS Success, Information Systems Research, 8(3), pp. 240-253.

Sekaran, Uma. 2006. Metodologi Penelitian untuk Bisnis. Edisi 4, Buku 1. Jakarta: Salemba Empat.

Stone, R., Good, D., and Eveleth, B. 2006. The Impact of Information Technology On Individual And Firm Marketing Performance, Behaviour \& Information Technology, 26(6), pp. 465 -482 . 